\title{
Yunnan Ethnic Educational Informatization Practice Innovation Helps Targeted Poverty Alleviation
}

\author{
Han Song ${ }^{1}$, , Luying Gan ${ }^{2}$ \\ ${ }^{1}$ Youth League Committee, Yunnan Open University, Kunming, China \\ ${ }^{2}$ College of Education, Yunnan Open University, Kunming, China

\section{Email address} \\ 37321880@qq.com (Han Song),cloudstory@126.com (Luying Gan) \\ ${ }^{*}$ Corresponding author
}

\section{To cite this article:}

Han Song, Luying Gan. Yunnan Ethnic Educational Informatization Practice Innovation Helps Targeted Poverty Alleviation. Science Innovation. Vol. 8, No. 5, 2020, pp. 134-138. doi: 10.11648/j.si.20200805.13

Received: February 8, 2020; Accepted: October 23, 2020; Published: November 4, 2020

\begin{abstract}
Education is an important means to help the poor to improve their quality and ability. With the further progress of targeted poverty alleviation, it can effectively change the phenomenon of "spiritual poverty" of some people and consolidate the basic effect of the country's targeted poverty alleviation strategy. How to better promote and link up the education and intellectual support work in the ethnic poor areas of Yunnan Province, to achieve education balance, and to get rid of poverty and become rich, is an important issue for governments and counterparts in many regions of Yunnan to think about. The author takes the "Education Informatization 2.0 Action Plan" issued by the Ministry of Education as the guide, and takes the Yunnan Open University's network cloud classroom construction and application in Wuding County, Yunnan Province as a practical case. Making an in-depth analysis of the important enlightenment from the new thinking of national educational informatization on strengthening the construction of ethnic education and facilitating targeted poverty alleviation in our province, so as to provide references for the accurate implementation of such work in the future.
\end{abstract}

Keywords: Educational Informatization 2.0 Action Plan, Yunnan Ethnic Educational Informatization, Targeted Poverty Reduction, Network Cloud Classroom

\section{云南民族教育信息化实践创新助力精准扶贫}

\section{${\text { 宋涵 }{ }^{*} \text {, 甘露荣 }}^{2}$}

云南开放大学团委, 昆明, 中国

2云南开放大学教育学院, 昆明, 中国

\section{邮箱}

37321880@qq.com（宋涵）, cloudstory@126.com（甘露芗）

\begin{abstract}
摘要：教育是扶智的重要手段，旨在提高贫困群众的素质和能力，随着精准扶贫深入推进，扶智可有效改变部分人的“精 神贫困”现象，夯实国家精准扶贫战略的基础效果。如何更好地促进和衔接云南民族贫困地区的教育和扶智工作，实现教 育均衡和脱贫致富, 是目前云南许多地区政府和对口帮扶单位思考的重要议题。笔者以国家教育部发布的《教育信息化 2.0 行动计划》为指导, 以云南开放大学在云南省武定县的网络云教室建设应用为实践案例, 深入探析当前国家教育信息 化新思路对我省加强民族教育建设, 助力精准扶贫所传递的重要启示, 以期为今后此类工作的精准实施提供参考。
\end{abstract}

关键词：教育信息化 2.0 行动计划, 云南民族教育信息化, 精准扶贫, 云教室 


\section{1. 引言}

云南省武定县是一个山区环境分布密集、少数民族聚 居、深度贫困人口多的云南省精准扶贫工作重点县域, 山 区面积占总面积的 $97 \%$, 少数民族人口占总人口的 $55 \%$, 2017 年末贫困人口占总人口的 $20 \%$ 。特殊的地理和人文环 境, 造成县内贫困群众, 特别是少数民族贫困群众文化程 度普遍较低、生产生活技能落后。同时, 由于受到山区地 理环境, 教育师资力量薄弱、教学资源短缺等问题的限制, 极大程度影响了当地少数民族群众对知识的需求和获取。 在当前国家大力开展教育信息化“三通工程”建设和全面 提升教育信息化基础支撑能力的有利条件下, 2018 年4 月 18 日, 国家教育部发布了《教育信息化 2.0 行动计划》

(以下简称《行动计划》) , 其中的“数字资源服务普及 行动”、“网络扶智攻坚工程行动”、“智慧教育创新发展行 动”对于打通武定县贫困地区教育“数字鸿沟”阻断, 有效 开展扶智工作，提供了具有前瞻性和可行性的行动指南。 [1]作为武定县的对口扶贫单位之一, 云南开放大学加依托 自身优势和特色, 多举措加大资金和人员投入, 努力开展 “造血式”扶贫。其中, 进行教育扶贫便是学校落实国家精 准扶贫任务的重点工作之一。随着学校在武定县委党校和 武定县高级职业中学两个网络云教室的建成和投入使用, 对当地的民族教育信息化发展和精准扶贫来说将会是一 项有益的实践创新。当前相关研究主要集中在“互联网+ 教育”相关领域, 本文以云南开放大学在云南省武定县的 网络云教室建设应用为实践案例, 深入探析当前国家教育 信息化新思路对我省加强民族教育建设, 助力精准扶贫所 传递的重要启示, 以期为今后此类工作的精准实施提供参 考。

\section{2. 《行动计划》新动向}

《行动计划》是为推进2016年教育部颁布的《教育信 息化“十三五”规划》蓝图的具体行动措施, 主要任务是实 现信息化的教与学、数字校园的建设覆盖各地各级学校和 师生, 它的出台对云南民族地区的教育发展和扶贫攻坚来 说, 有三个值得我们关注和参考的新动向。

\section{1. “数字资源服务普及行动”}

“数字资源服务普及行动”是实施教育大资源共享计 划, 拓展完善国家数字教育资源公共服务体系, 推进开放 资源汇聚共享, 打破教育资源开发利用的传统壁垒, 利用 大数据技术采集、汇聚互联网上丰富的教学、科研、文化 资源, 为各级各类学校和全体学习者提供海量优质的学习 资源服务, 实现从“专用资源服务”向“大资源服务”的转变。 [3]而云南开放大学则是由云南省人民政府主办、省教育厅 主管, 秉承开放共享办学理念, 在全省建设了23所州市、 县区、行业二级开放学院, 23 个县 (区) 学习中心、132 个教学点, 通过网络在线远程教育平台和提供大量数字学 习资源, 面向全体社会成员, 坚持学历教育与非学历教育 并举，致力于为当地培养应用型人才，从而有力的支撑当 地社会经济发展和扶贫攻坚。

\section{2. “网路扶智工程攻坚行动”}

“网路扶智工程攻坚行动”是针对新时期精准扶贫中 出现的“精神贫困”现象，所强调的“要坚持扶贫同扶志扶 智相结合, 以激发脱贫致富的内在动力”、“扶贫必扶智” 科学论断的教育信息化发展新方向。[4]“网路扶智工程攻 坚行动”旨在引导教育发达地区与薄弱地区通过信息化实 现结对帮扶，通过相关社会企事业机构的支持，在“三区 三州”开展“送培到家”活动, 以推动开放大学云教室建设, 开展信息化教学设备捐赠、优质数字教育资源共享、落实 教育扶贫和网络扶贫的为重点任务, 服务地方, 提升深度 贫困地区教育质量和人才培养能力, 推动当地社会经济发 展。

\section{3. “智慧教育创新发展行动”}

“智慧教育创新行动”是开展智慧教育创新示范, 依托 网络及各类智能设备, 将人工智能、大数据、物联网等新 兴技术作为基础积极开展智慧教育创新研究和示范, 推动 新技术支持下教育的模式变革。[5]

\section{3. 云南开放大学在武定县开展“造血式”扶贫和 扶智过程中所面临的问题}

\section{1. 帮扶对象普遍文化水平较低, 现代生产技能、知识 缺乏}

云南开放大学在武定县开展“造血式”扶贫过程当中 时发现, 帮扶对象多是少数民族群众, 他们普遍存在文化 基础差、生产技能单一、忽视对年轻一代的文化教育。所 以, 在帮助他们找项目、引项目、推项目的同时, 贫困群 众以及他们年轻一代的文化素质和生产技能迫切需要得 到提升, 并且需要大力转变他们的思想观念, 坚定他们的 脱贫致富信心, 激发他们的脱贫内动力, 消除“被动脱贫” 和“被扶贫”的“精神贫困”现象。[6]

\section{2. 地理环境特殊, 教育基础薄弱, 开展扶智工作难度 大、成本高}

扶智主要是通过基础教育、生产技能和创业知识培训 等手段, 增强贫困群众的知识和技能水平, 提高生产力。 [7]如前文所述, 武定县少数民族贫困群众主要杂居或散居 在山区和半山区, 道路交通不便, 虽然中央和地方投入大 量人力物力, 新建各类教育基础设施, 但和省内外城市地 区相比, 依然存在办学条件差、师资力量薄弱、教学质量 不高等问题。以目前的实施情况看, 传统的面授教育模式 存在投资大、所需师资力量缺乏、设施设备利用率低等诸 多现实问题。

\section{3. 少数民族贫困群众者文化程度和学习需求纷繁不一, 传统扶智模式难以应对}

这些贫困群众文化程度各不相同, 且三十岁以上者文 盲半文盲者不少, 他们的学习能力、技能需求也不尽相同, 
传统的教育模式应对如此复杂的学习受众情况明显力不 从心, 缺乏有效的针对性, 教育需求与供给之间严重不平 衡。他们的年轻一代同样面临当地学校教育质量不高、优 秀教育资源短缺、学习积极主动性不高等问题, 为防止贫 困的代际传递, 迫切需要一种新的, 且行之有效的扶智模 式来应对。[8]

\section{4. 发挥自身优势和特色, 把云教室建设和应用 作为解决当地教育扶智困难的着力点和创新 点}

\section{1. 云教室建设和充分发挥作用的时机已经成熟}

按照《行动计划》和政府持续通信基础设施建设力度, 据云南省统计局政务公开内容显示, 截至2017年12月, 全 省 $97 \%$ 以上村镇实现网络覆盖, 人们只要到有云教室的地 方, 就可以通过云教室和与之配合网络教学平台 (终端), 直播和点播他们所需要的全国乃至全球优秀教学过程和 教育资源, 海量资源供给几乎可以满足当地贫困群众和帮 扶干部各个层次、各种知识技能的多维复杂需求组合。[9]

\section{2. 武定县云教室的建设简介}

云教室系统是以优质教学和资源的远程在线互动和 共享为核心, 以数字化设备为基础, 以云平台为依托, 以 传播优质教育资源为目标, 以及时动态反馈为特征的新技 术多媒体教学环境的集合。[10]云教室系统不仅具有远程 授课、视频会议、考试监控等三位一体的功能, 同时还可
支持各种网络条件下远程双向高清视频、网上实时教学、 网上大规模直播教学、视频监控、双向互动教学、公开课 评审、多地教学教研、学术交流、课程实时录播、课程实 时点播、课件资源管理、在线答疑等功能。[11]

云教室系统建设项目是一项系统性工程, 整个项目以 云南开放大学总部为中心, 各二级开放学院、学习中心为 纽带, 基层教学点为载体, 利用现代信息技术, 依托《行 动计划》当中的“三通”互联网网络, 建设互联互通的云教 室系统。其中武定县的云教室定位基层教学点, 作为教育 扶贫培训中心和开放教育教学点共享共用, 所需设备物料 由总部捐赠, 教室由武定县委党校和武定高级职业中心装 修的共建共管共用模式, 最大限度的提高项目费效比和利 用率。(系统建设架构如图一所示)

\section{3. 武定县云教室使用情况}

武定县的云教室系统建成以后, 可以实施互动教学、 教学教研、视频会议、课件资源管理等。通过云教室平台 实现优质教育资源共享, 甚至是多个不同地理位置教学点 “同上一节课”, 可有效解决学校在当地贫困群众脱贫扶智 的“多维度适配”问题, 为“造血式”扶贫真正取得实效提供 有力支持。从2018年3月起, 总部已开始定期进行两个云 教室的教学安排, 服务于当地各类教育扶智培训和开放教 育教学, 定期通过网络平台发布教学效果问卷和学习需求 问卷, 评估

教学效果, 收集生产技能培训需求, 受到当地师生的 一致好评。

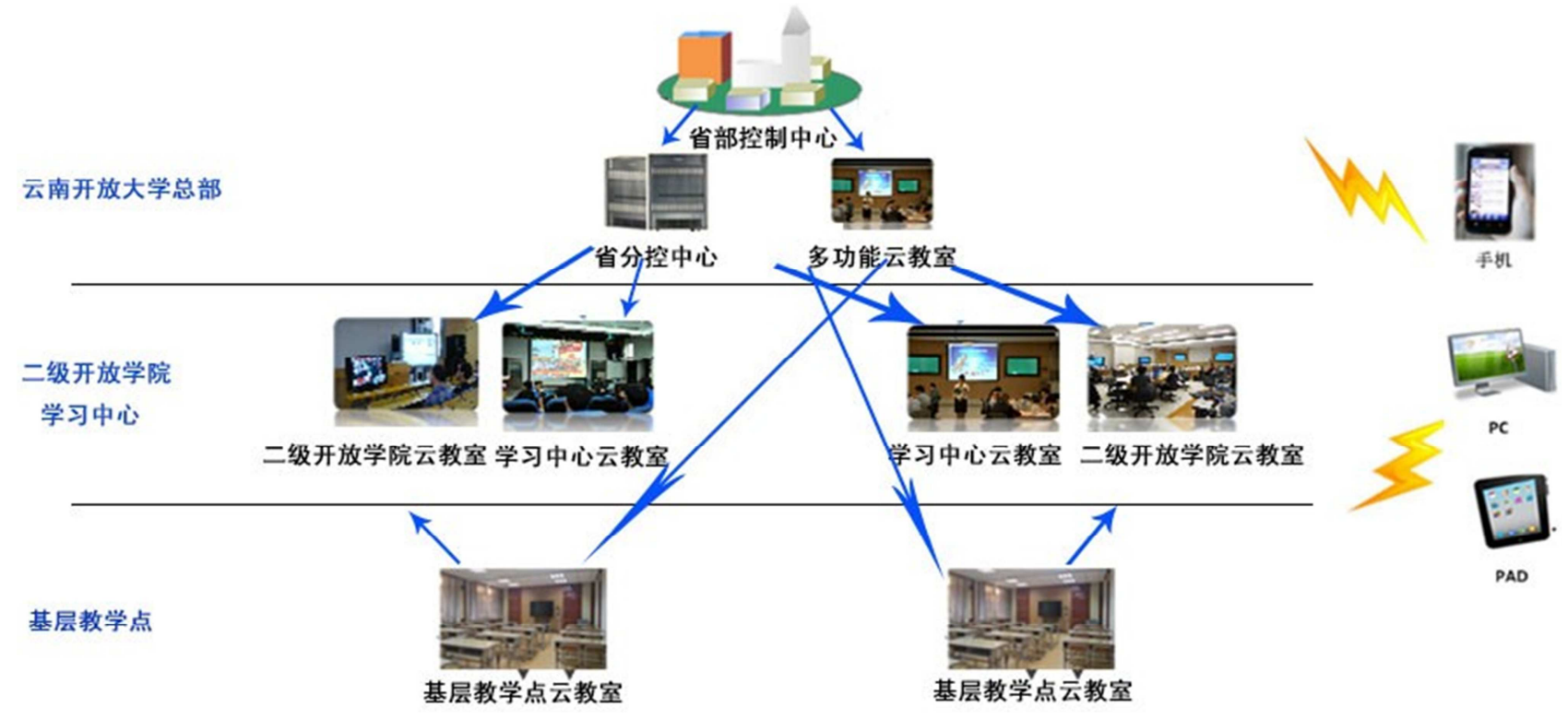

图1 云南开放大学云教室建设系统架构图。

\section{5. 云教室应用实践在武定县民族教育和精准扶 贫中的创新意义}

针对武定县的网络扶智是云南开放大学“造血式”精 准扶贫工作中的重要一环, 通过这种教育方式的创新实践,
能快速提高当地人民群众特别是少数民族贫困群众的综 合素质和生产技能, 解决他们的各层次、各类型学习需求 组合、提供优质教学资源的同时大大降低成本, 提高工作 效率, 通过云教室进行技能扶贫、技术扶贫和素质扶贫, 保障我校精准扶贫工作落到实处。通过试点应用证明, 这 是一种行之有效且符合当地实际的实践创新。[12] 


\section{1. 云教室应用实践是有效服务于当地的数字资源均衡 普及和共享的创新}

由于地理、经济、人文等多种原因, 当地优质教育资 源匮乏, 教育基础薄弱, 这种情况在一段时间内无法完全 解决, 因此限制了教育和扶智的开展。在当地政府持续加 大教育基础投入的同时, 作为以信息化远程教育为特色的 对口帮扶单位, 在人财物有限的条件下, 开展云教室应用 实践, 解决当地教育和教育资源供给矛盾, 只要能够接入 互联网, 就可以用云教室共享各种教育资源。[13]有利于 实现教育资源的充分共享和高效利用、节约单位自筹扶贫 资金成本，用先进教育信息化手段化解当地具体教育和扶 贫实际困难, 有效提高受帮扶贫困群众的“造血”能力和脱 贫信心，为当地民族教育事业开辟了一条新路径。

\section{2. 云教室应用实践是适应当地民族教育实情的网络扶 智攻坚创新}

据《武定县2018年政府工作报告》相关所述统计数据, 随着当地政府对信息网络基础设施不断完善, 乡镇、行政 村光缆覆盖率已达 $100 \%$, 政府把全面实施教育扶贫作为 扶贫首要工作, 深入推进“互联网+”精准社会扶贫。在这 样有利条件下, 云南开放大学积极秉承自己开放办学特色 和终身教育的理念, 利用现代信息技术使教育更好的服务 当地精准扶贫攻坚, 用实际行动推进网络条件下的精准扶 智, 以云教室的建设和应用为接入点, 通过网络教学平台 和直播通道, 实现扶智结对的落地生根。[14]对贫困地区 群众或适龄学生定期开展各种以云教室为载体的实时非 实时优质网络课堂教学双向互动传递, 实现“互联网+”条 件下的区域教育资源均衡供给, 缩小城乡、民族教育差距。 这是当地政府、教育部门、学校与云南开放大学共同努力 的成果, 是结合当地实际的网络扶智攻坚行动实践创新。

\section{3. 云教室应用实践是配合当地教育信息化建设的智慧 教育创新发展}

对于武定县的教育信息化发展，当地政府和教育部门 高度重视，按照国家教育信息化十三五规划积极开展“三 通两平台”建设, 但是受限于当地特殊环境和经济文化基 础, 对于智慧教育的理论研究、顶层设计、整合人工智能、 大数据、物联网等新兴技术实践应用方面与发达地区存在 巨大的差距。云教室的应用实践可让当地的教育教学融入 到全国智慧教育大平台当中去, 推动当地教育理念与模式、 教学内容与方法的改革创新, 更智能的满足当地民族教育 和精准扶贫全时空、全受众的精准适配新要求, 开展知识 传授和劳动能力培养的智慧教育。[15]

\section{6. 结论}

云南开放大学在武定县开展“造血式”扶贫和扶智过 程中面临了诸多困境, 我们应充分发挥学校办学优势和特 色, 把云教室建设和应用作为解决当地教育扶智困难的着 力点和创新点, 服务于当地的数字资源均衡普及和共享, 通过网络扶智攻坚、促进当地教育信息化建设, 打赢扶贫 攻坚战。当前, 教育信息化 2.0 行动刚刚启动, 如何更好
地推进民族地区的教育发展和精准扶智, 还要在实践当继 续总结完善, 同时, 我们也要紧跟国家创新理念指引, 要 解放思想, 要开展前瞻性理论研究, 积极开展以“人工智 能 + 大数据”驱动的少数民族贫困地区师生教育资源智能 供给平台开发，在线虚拟仿真实验室、生产线、种植基地 等智慧学习空间建设, 基于区块链、大数据等新技术的学 习效果记录、转移、交换、认证等数据精准记录实现等进 行研究, 让信息技术和人工智能技术深度融入当地教育教 学全过程, 用教育信息化新技术的精准扶智, 努力消除少 数民族贫困地区的“数字鸿沟”, 阻断贫困的代际传递, 最 终打赢这场扶贫攻坚战。

\section{致谢}

此论文完成之际, 首先向课题组所有成员表示最衷心 感谢和最诚挚的敬意。各位老师在调研和后期数据分析时 给予我很大帮助。衰心感谢所有关心和帮助我的人, 谢谢 你们。

本文为云南省教育厅科研基金资助项目《“互联网+ 教育” 背景下推进云南省民族教育均衡发展探索研究》(项 目编号：2018JS374)的阶段性成果之一。

\section{参考文献}

[1] Carolan. SimFection: a digital resource for vaccination education[J].Journal of Biological Education, 2019, (2) .

[2] 陈岩, 宋国权. “扶智”在精准扶贫中的长效作用及实践路 径[J].中国市场. 2019，(5)。

[3] 赵琰. 基于信息化建设的智慧教育发展探究[J].信息记录材 料, 2019, (2).

[4] 姚新, 霞张鹏, 杨晋娟. 利用云教室促进贫困地区远程高 等教育均衡发展研究——来自新疆广播电视大学的实践 $[\mathrm{J}]$. 现代教育技术，2018，（8）。

[5] 罗江华. 以信息技术应用促进民族教育现代化[J].教育发展 研究, 2017, (17).

[6] 陈耀华, 陈琳.互联网+教育智慧路向研究 [J].中国电化教育, 2016 (9) : 80-84, 135.

[7] 冯永,钟将, 叶春晓等. 海量数字教育资源管理和共享的云服 务模型研究 [J].中国电化教育,2013(5).

[8] 秦虹, 张武升. “互联网+教育”的本质特点与发展趋向 [J]. 教 育研究, 2016（6）：8-10.

[9] 陈娟娟,孙瑜,田莉等. 民族教育信息资源数字化现状分析与 归因、对策的研究[J].中国电化教育,2013(7).

[10] 戴维· $\mathrm{H}$ ·乔纳森. 学会解决问题:支持问题解决的学习环境设 计手册[M].上海:华东师范大学出版社,2015.

[11] 黎静. 对远程学习者加强反馈服务的思考 [J]. 吉林广播电视 大学学报, 2010(10): 78-79. 
[12] 陈正勇. 高等教育大众化视野中的应用特色型大学人才质 量观审视[J].教育教学论坛, 2011, (17).

[13] 黄小云, 黄海蓉. 开放教育教学资源共建共享——现实 困境与路径机制为中心的探讨 [D]. 河北广播电视大学 学报, 2012, 17(4).
[14] 田季生, 孔令军. 远程教学资源区域共建共享: 现实形态 与精神重构 $[\mathrm{J}]$.中国远程教育, 2010，(2).

[15] 宋乃庆, 杨欣, 李玲. 以教育信息化保障城乡教育一体化 [J].电化教育研究, 2013, (2). 